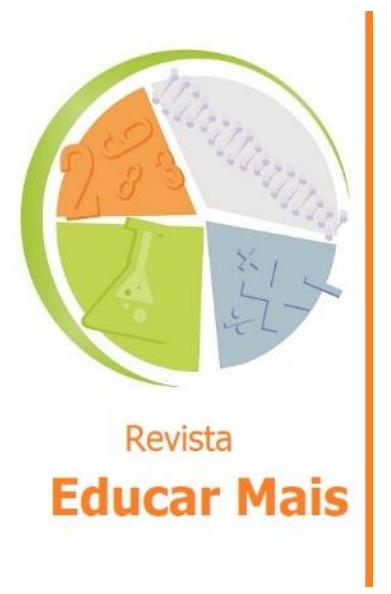

\title{
Desempenho estudantil no Ensino Superior: um olhar para as perspectivas discentes e docentes
}

\author{
Student performance in Higher Education: a look at learners and \\ professors' perspectives
}

\section{Desempeño estudiantil en la Enseñanza Superior: una mirada hacia las perspectivas docentes $y$ discentes}

Valesca Brasil Irala ${ }^{1}$; Natália Nara Janner ${ }^{1}$; Elenilson Freitas Alves ${ }^{1}$; Alexandre Denes Arruda ${ }^{1}$; Cristiano Ribeiro Martins ${ }^{1}$

\section{RESUMO}

Considerando que o número de reprovações em disciplinas cursadas pode acarretar em evasão no Ensino Superior, este trabalho objetivou elencar as disciplinas que apresentam piores índices de desempenho estudantil no campus Bagé da instituição multicampi Universidade Federal do Pampa (UNIPAMPA), bem como as causas apontadas tanto pelos discentes quanto pelos docentes em relação a esse tópico. Para tal, foram analisados dados extraídos do sistema de gestão acadêmica, compreendidos por um período de sete anos, para o levantamento longitudinal das disciplinas com maiores índices de reprovação no campus em questão. Em uma segunda etapa, foram aplicados questionários respondidos anonimamente pelos discentes e docentes, a fim de identificar suas percepções sobre o assunto. A maioria das disciplinas com índices mais altos de reprovação pertence à área das Ciências Exatas e são ofertadas ao longo dos primeiros semestres dos cursos de graduação. Concluiu-se que a melhoria do desempenho estudantil pode ser conduzida através da implementação de algumas ações conjuntas e interdependentes, ou seja, pela esfera institucional, no campo da docência e, também, no âmbito da ampliação do engajamento discente.

Palavras-chave: Desempenho estudantil; Educação Superior; Avaliação; Universidade Federal do Pampa.

\begin{abstract}
Considering that the number of failures in subjects taken can lead to dropout in Higher Education, this study aimed to list the subjects with the worst student performance rates at the Bagé campus of the multicampi institution Universidade Federal do Pampa (UNIPAMPA), as well as the causes pointed out by both students and professor in relation to this topic. In order to this, data extracted from the academic management system, understood for a period of seven years, were analyzed for the longitudinal survey of the subjects with the highest failure rates on the campus in question. In a second step, questionnaires were answered anonymously by students and professors, in order to identify their perceptions on the topic. Most of the subjects with the highest failure rates belong to the Exact Sciences area and are offered throughout the first semesters of undergraduate courses. It was concluded that the improvement of student performance can be achieved through the implementation of some joint and interdependent actions, that is, by the institutional sphere, in the field of teaching and, also in the scope of expanding student engagement.
\end{abstract}

Keywords: Student performance; Higher Education; Assessment; Universidade Federal do Pampa.

\footnotetext{
${ }^{1}$ UNIPAMPA - Universidade Federal do Pampa, Bagé/RS - Brasil.
} 


\section{RESUMEN}

Al tener en cuenta que el número de fracasos en las asignaturas tomadas puede conducir a la deserción en la educación superior, este estudio tuvo como objetivo enumerar las asignaturas con las peores tasas de rendimiento estudiantil en el campus Bagé de la institución multicampi Universidade Federal do Pampa (UNIPAMPA), así como las causas señaladas por estudiantes y profesores con respecto a ese tema. Para eso, fueron extraídos datos del sistema de gestión académica, abarcando un período longitudinal de siete años, en que se identificó en cuáles asignaturas había las tasas de fracaso más altas en el campus en cuestión. En un segundo paso, los cuestionarios fueron contestados anónimamente por estudiantes y docentes, con el fin de identificar sus percepciones sobre el tema. La mayoría de las asignaturas con las tasas de fracaso más altas pertenecen al área de Ciencias Exactas y se ofrecen durante los primeros semestres de las carreras de pregrado. Se concluyó que la mejora del rendimiento de los estudiantes se puede lograr a través de la implementación de algunas acciones conjuntas e interdependientes, es decir, por parte de la esfera institucional, en el campo de la enseñanza y, también, en el ámbito de la expansión del compromiso de los estudiantes.

Palabras clave: Desempeño estudiantil; Educación Superior; Evaluación; Universidade Federal do Pampa.

\section{INTRODUÇÃO}

A Lei das Diretrizes e Bases da Educação Nacional (1996) estabelece como finalidade da Educação formal o desenvolvimento do indivíduo, preparando-o para exercer a cidadania e qualificando-o para entrar no mundo de trabalho. Dessa forma, uma das grandes responsáveis pelo crescimento pessoal e, também, pelo desenvolvimento econômico e social de um país é a Educação, especialmente em nível universitário. A partir dos primeiros anos do século XXI, o Governo Federal instituiu vários programas visando ampliar o acesso da população às Instituições Públicas de Ensino Superior (GENTIL, 2017). É indiscutível que o número de vagas ofertadas nas universidades através desses programas sofreu um grande aumento nesse período. Contudo, esse aspecto não é suficiente para garantir que a grande maioria dos ingressantes no Ensino Superior permaneça até atingir a diplomação.

Nesse quadro de expansão da primeira década deste século, o Ministério da Educação (MEC) firmou um acordo com a Universidade Federal de Santa Maria (UFSM) e a Universidade Federal de Pelotas (UFPel), a fim de promover a ampliação da oferta de cursos de graduação na mesorregião sul do estado do Rio Grande do Sul. Desse acordo, surgiu a Universidade Federal do Pampa, fundada através da Lei no 11.640, de 11 de janeiro de 2008 (BRASIL, 2008).

A reitoria da instituição é sediada no município de Bagé e a universidade possui estrutura multicampi, com unidades nos municípios de Bagé, Caçapava do Sul, Dom Pedrito, Santana do Livramento, Jaguarão, Uruguaiana, Itaqui, Alegrete, São Borja e São Gabriel, todos localizados no estado do Rio Grande do Sul, estabelecendo fronteira com o Uruguai e a Argentina, onde há a oferta de cursos presenciais. Fora essas unidades, hoje a UNIPAMPA também conta com polos de educação a distância em outros 21 municípios do estado. Um dos objetivos em fundar uma universidade federal nessa região foi o de reduzir a estagnação econômica, promovendo o seu desenvolvimento em vários níveis (MARCHIORO et al., 2007).

O maior campus da Universidade Federal do Pampa é o campus Bagé, que oferta 525 novas vagas de graduação em modalidade presencial a cada ano (UNIPAMPA, [s.d.]). São ofertados, em turno integral, os cursos de Engenharia de Alimentos, Engenharia de Energia, Engenharia Química, 
Licenciatura em Física, Licenciatura em Letras - Línguas Adicionais Inglês, Espanhol e Respectivas Literaturas, Licenciatura em Música e Licenciatura em Química; e, em turno noturno, são ofertados os cursos de Engenharia de Computação, Engenharia de Produção, Licenciatura em Letras Português e Literaturas de Língua Portuguesa e Licenciatura em Matemática.

Em termos de organização acadêmica, a universidade não apresenta estrutura departamental. Assim, os componentes curriculares são atrelados aos cursos de cada campus e, a partir disso, é estabelecido, de forma compartilhada entre todos os cursos do campus, o rol de componentes curriculares, número de vagas por curso em cada componente e seus horários de oferta.

Este artigo, desenvolvido no âmbito do Grupo de Pesquisa sobre Aprendizagens, Metodologias e Avaliação (GAMA - registrado no Diretório de Grupos de Pesquisa do CNPq), visa apresentar um estudo descritivo (RAUEN, 2006), de caráter misto, tanto quantitativo quanto qualitativo, o qual visa identificar, longitudinalmente (um período compreendido em sete anos, ou seja, quatorze semestres letivos), quais foram as disciplinas com maior reprovação por nota e por frequência, bem como identificar, no âmbito das disciplinas com maior índices de reprovação, quais fatores foram intervenientes no processo, a partir da perspectiva dos docentes ministrantes e dos discentes que não apresentam um desempenho acadêmico satisfatório. Na próxima seção, apresentaremos uma breve síntese dos estudos que embasam esta pesquisa.

\section{BREVE REVISÃO DA LITERATURA}

Tinto $(1975,1993,2012,2017)$ tem proposto, há mais de três décadas, um modelo sociológico para explicar o fenômeno da evasão, baseado na Teoria do Suicídio de Durkheim. O autor buscou explicar a evasão a partir da integração acadêmica e social por parte do discente, entendendo que o estudante toma a decisão de evadir de maneira voluntária, apesar de ser influenciado pela intensidade do contato desenvolvido com a universidade. Para ele, quando decide evadir, o indivíduo é motivado, entre outras razões de cunho pessoal, pela dificuldade de adaptação com a rotina universitária e pelo sentimento de insatisfação com o seu desempenho acadêmico.

Segundo Lobo (2012), para realizar um estudo sobre reprovação, evasão, retenção e similares, é necessário compreender o cenário atual do Ensino Superior brasileiro. No início do século XXI, houve um grande crescimento do número de Instituições de Ensino Superior, ocasionado pela implementação de programas do governo que visavam expandir o seu acesso. Apesar dos esforços pela expansão de vagas ofertadas em cursos de graduação, a permanência dos discentes ainda recebe pouca atenção enquanto política pública (CATANI; HEY; GILIOLI, 2006). Há diversos estudos que tratam das possíveis causas de fenômenos como evasão, reprovação e retenção; no entanto, eles constatam que são aspectos extremamente complexos e multifatoriais. Isso porque estão diretamente relacionados com fatores dos âmbitos pedagógicos, psicológicos, sociais, administrativos, entre outros (DIOGO et al., 2016).

É indiscutível que uma das variáveis determinantes para a tomada da decisão de evadir da Educação Superior é o número de reprovações. $O$ insucesso acadêmico acaba desestimulando o aluno a investir tempo e recursos financeiros para a conclusão da graduação (AMARAL, 2009). Leite e Kager (2009) realizaram um estudo em que constatam marcas aversivas apontadas pelos discentes como associadas à avaliação. Entre elas, destacam-se: o sentimento de medo e ansiedade nos momentos que antecedem as avaliações; o sentimento de incapacidade, de se sentir "burro" quando os resultados das avaliações não são positivos; a perda da motivação e interesse pela disciplina como 
consequência das notas baixas das avaliações; a frustração e exclusão pelo fato de necessitarem repetir a disciplina; e, ainda, a deterioração da relação sujeito-objeto, ou seja, os alunos criam aversão à disciplina quando vivenciam experiências negativas com as avaliações.

Um estudo semelhante ao proposto pelo presente artigo foi realizado por Missiol et al. (2016), que obteve os dados de retenção e evasão do curso de Medicina Veterinária da UNIPAMPA. Segundo esse estudo, os maiores índices de reprovação são observados no ciclo básico inicial do curso; quanto às reprovações ocorridas em componentes curriculares pertencentes ao ciclo profissionalizante, os autores as relacionam à complexidade dos conteúdos, às metodologias adotadas pelos docentes e à baixa dedicação dos discentes aos estudos. Além disso, tal estudo aponta como principais causas da evasão e da retenção: o déficit em conhecimentos de componentes curriculares por parte dos discentes, que pode estar associada a falhas ocorridas ainda na Educação Básica; bem como às metodologias adotadas pelos docentes, que podem afetar o desempenho discente, principalmente dos ingressantes, que apresentam dificuldades para se adaptar à condução da vida universitária, a qual lhes exige um maior grau de autonomia do que nos níveis de ensino anteriores, entre outros fatores.

Jacomini (2009) aponta a reprovação como uma maneira de resolver os problemas ocasionados pelo baixo desempenho escolar do aluno, resultante das defasagens do ensino básico no Brasil. A responsabilização pelas reprovações, no quadro das instituições, acaba recaindo sobre o próprio discente, contudo, há diversos fatores sociais e educacionais que o cercam e, também, acabam por influenciar nesses resultados. Mendes (2005) evidencia que a avaliação através de provas e notas é um modelo tradicional e inadequado e propõe que a avaliação deve ser vista como um processo contínuo, em que o docente observa o aluno constantemente, identificando as suas dificuldades e buscando fornecer auxílio para superá-las. Dessa forma, a reprovação tende a diminuir, já que a nota deixa de ser a motivação para o estudo e se torna apenas uma consequência.

A problemática encontrada no Brasil quanto às evidências negativas do processo avaliativo em termos unicamente de aprovação ou reprovação e de seus efeitos para os discentes (em vários níveis) e, consequentemente para as instituições (quando atingem como resultado a evasão) não é exclusividade ou um fato isolado das instituições brasileiras, como podemos identificar em vários estudos internacionais, seja focados em avaliação, seja focados em evasão (ANDERTON; EVANS; CHIVERS, 2016; GONZÁLEZ-CAMPOS; CARVAJAL-MUQUILLAZA， ASPEÉ-CHACÓN, 2020; HERNÁNDEZ-JIMÉNEZ et al., 2020; LÓPEZ-PASTOR, 2017; MORENO; CHIECHER, 2019; SOUSA; OLIVEIRA; BORGES, 2018). Diferentes enfoques e frentes de ação são necessários para incidir de forma sistemática e responsiva ao cenário da evasão e, um dos caminhos para uma compreensão situada dos fenômenos está em poder compreender a perspectiva dos agentes diretamente envolvidos no processo de ensino-aprendizagem, ou seja, os professores e os discentes. Dito isso, apresentamos a metodologia da pesquisa.

\section{METODOLOGIA}

Para realizar um levantamento das disciplinas que causam maior reprovação dos alunos no campus Bagé da Universidade Federal do Pampa, foram analisados todos os componentes curriculares ofertados por um período de sete anos. Cabe ressaltar que, neste artigo, os termos "componente curricular" e "disciplina" são tomados como sinônimos. Conforme UNIPAMPA (2016b), o primeiro termo é utilizado na instituição para se referir a qualquer unidade curricular prevista em uma matriz 
de integralização, tendo horário fixo, turma definida e docente(s) com carga horária atribuída, sendo exigido pelo menos $75 \%$ de frequência para o aluno matriculado. Em outras Instituições de Ensino Superior, é comum atribuir o termo "disciplina" para uma organização didática semelhante, por isso, optamos por manter as duas nomenclaturas.

Conforme a Resolução n 29 de 28 de abril de 2011 da UNIPAMPA (2011), a referida universidade prima pela avaliação do discente como sendo processual, contínua e cumulativa, prevalecendo aspectos qualitativos sobre os quantitativos, sendo necessário pelo menos um documento físico (provas, relatórios ou demais instrumentos) para registrar os resultados de aprendizagem. Ao fim dos processos de avaliação, é atribuída uma nota numérica, que pode assumir um valor de 0 (zero) a 10 (dez). Nos cursos presenciais, o resultado final da avaliação é expresso como aprovação ou reprovação, sendo aprovado no componente o discente que possuir nota maior ou igual a 6 (seis), além de, no mínimo, $75 \%$ de frequência.

Os dados foram extraídos do sistema institucional e listaram o número total de alunos matriculados nos componentes, e, desses, quantos foram aprovados, quantos foram reprovados por frequência e quantos foram reprovados por nota. Em um primeiro momento, os componentes foram analisados separadamente, por curso de graduação. Posteriormente, os dados dos cursos foram confrontados, para que fosse possível levantar os índices gerais de reprovação no campus.

$\mathrm{Na}$ análise realizada para cada curso de graduação, calculou-se a porcentagem de aprovação através da razão entre o número total de alunos aprovados e o número total de alunos matriculados nas disciplinas ofertadas no período de tempo definido para a análise. Um cálculo semelhante foi aplicado para encontrar a porcentagem de reprovações por nota (razão entre reprovados por nota e matriculados) e de reprovações por frequência (razão entre reprovados por frequência e matriculados).

O campus Bagé possui alguns componentes de natureza multicurso, ou seja, são aqueles ofertados para mais de um curso de graduação, principalmente nos chamados núcleo de conteúdos básicos e profissionalizantes (CNE, 2002). Conforme dados do sistema institucional, no campus Bagé, são ofertados em média 310 componentes curriculares por semestre, dos quais 55 são comuns a mais de um curso de graduação. Sendo assim, aproximadamente $18 \%$ das componentes curriculares do campus são de natureza multicurso. Tendo em vista tais componentes, os quais acabam sendo idênticos ou equivalentes em mais de um curso de graduação, foi possível agrupar os índices obtidos nos diferentes cursos para o mesmo componente, de modo que fosse possível analisar os índices gerais de aprovação e reprovação no referido campus. Dessa forma, foi obtida a porcentagem de alunos reprovados por frequência, reprovados por nota e aprovados em cada uma das disciplinas ofertadas. Sendo assim, foi feita a relação das dez disciplinas que possuem índices mais altos de reprovação no campus Bagé da Universidade Federal do Pampa, reunindo-as em três classificações: menores índices aprovação, maiores índices de reprovação por nota e maiores índices de reprovação por frequência.

Em um segundo momento, foi elaborado um questionário aplicado anonimamente aos estudantes reprovados por nota e por frequência em duas disciplinas com baixos índices de aprovação. Foram escolhidos os componentes curriculares de Cálculo II e Física I, por serem disciplinas obrigatórias para a maioria dos cursos de graduação ofertados no campus Bagé. O questionário foi enviado para todos os alunos reprovados nesses dois componentes no semestre anterior ao momento da coleta dos dados e era composto por duas perguntas fechadas e duas perguntas abertas. 
A pergunta 1 era fechada e se referia ao turno no qual o estudante cursou o componente em que foi reprovado, tendo duas opções de resposta: tarde e noite. A pergunta 2 também era fechada e se referia ao modo de reprovação do aluno no componente, tendo duas opções de resposta: reprovação por nota ou reprovação por frequência. A pergunta 3 era aberta e solicitava que o discente descrevesse os motivos que ele considera que o levaram a sua reprovação. A pergunta 4 também era aberta e solicitava que o aluno enumerasse quantas vezes já cursou a disciplina em questão.

Posteriormente, foi elaborado um segundo questionário, também anônimo. Dessa vez, para os professores responsáveis por ministrar, nos últimos três anos anteriores à coleta dos dados, os componentes que foram apontados com os menores índices de aprovação, maiores índices de reprovação por nota e maiores índices de reprovação por frequência, e era composto por três perguntas, sendo uma fechada e duas abertas.

A pergunta 1 era fechada e solicitava que o professor indicasse a categoria da disciplina que ministrou, a partir dos critérios tabulados previamente pelos pesquisadores, ou seja: a) menor índice de aprovação; b) maior índice de reprovação por nota; c) maior índice de reprovação por frequência (poderia haver sobreposição e o docente indicar mais de um critério entre os indicados). A pergunta 2 era aberta e solicitava que o docente apontasse as causas que levaram o seu componente a ter altos índices de reprovação ou baixos índices de aprovação. A pergunta 3 também era aberta e solicitava que o docente apontasse sugestões que pudessem auxiliar na redução dos índices de reprovação. Feita a apresentação dos procedimentos metodológicos, passamos para os resultados e discussões.

\section{RESULTADOS E DISCUSSÃO}

Finalizados os cálculos para encontrar a porcentagem geral de aprovados, reprovados por nota e reprovados por frequência no campus Bagé, foi possível obter listas contendo os componentes curriculares com índices de reprovação mais expressivos. Os dez menores índices de aprovação, em ordem crescente, foram identificados nas disciplinas dispostas na Tabela 1.

Tabela 1: Componentes curriculares que apresentaram menores índices de aprovação.

\begin{tabular}{cc}
\hline Componente curricular & Índice de aprovação \\
\hline Física Geral I & $20,09 \%$ \\
Algoritmos e Programação & $27,36 \%$ \\
Física I & $28,64 \%$ \\
Cálculo II & $29,38 \%$ \\
Cálculo I & $30,70 \%$ \\
Cálculo III & $30,94 \%$ \\
Fundamentos de Matemática Elementar & $31,00 \%$ \\
Introdução à Arquitetura de Computadores & $32,74 \%$ \\
Física Geral III & $34,88 \%$ \\
Geometria Analítica & $35,04 \%$ \\
\hline
\end{tabular}

Fonte: Autores (2020).

Os dez componentes curriculares que apresentaram maiores índices de reprovação por nota, em ordem decrescente, estão dispostos na Tabela 2. 
Tabela 2: Disciplinas que apresentaram maiores índices de reprovação por nota.

\begin{tabular}{cc}
\hline Componente curricular & Índice de reprovação por nota \\
\hline Teoria Elementar das Funções & $49,73 \%$ \\
Fenômenos de Transporte II & $47,73 \%$ \\
Cálculo III & $46,23 \%$ \\
Química Orgânica II & $44,46 \%$ \\
Cálculo I & $39,73 \%$ \\
Física Geral III & $39,53 \%$ \\
Química Analítica Qualitativa & $39,49 \%$ \\
Bioquímica & $39,19 \%$ \\
Conversação em Espanhol & $39,13 \%$ \\
Física Geral I & $38,39 \%$ \\
\hline
\end{tabular}

Fonte: Autores (2020).

Por fim, os dez maiores índices de reprovação por frequência, em ordem decrescente, foram constatados nas disciplinas que estão dispostas na Tabela 3.

Tabela 3: Disciplinas com maiores índices de reprovação por frequência.

\begin{tabular}{cc}
\hline Componente curricular & Índice de reprovação por frequência \\
\hline Produção Acadêmico-científica & $49,21 \%$ \\
Softwares na Aprendizagem de Matemática & $44,83 \%$ \\
Introdução à Arquitetura de Computadores & $43,70 \%$ \\
Física Geral I & $41,52 \%$ \\
Algoritmos e Programação & $40,40 \%$ \\
Geometria Plana & $39,24 \%$ \\
Estrutura de Dados & $38,37 \%$ \\
Laboratório de Física I & $36,59 \%$ \\
Arquitetura e Organização de Computadores I & $36,48 \%$ \\
Fundamentos da Língua Portuguesa & $36,04 \%$ \\
\hline
\end{tabular}

Fonte: Autores (2020).

No campus Bagé, a disciplina de Física Geral I é ofertada apenas ao curso de Licenciatura em Física, sendo alocada no primeiro semestre. É composta por seis créditos teóricos e é ministrada pelos docentes da Licenciatura em Física (UNIPAMPA, 2018b). A componente curricular Algoritmos e Programação é ofertada no primeiro semestre do curso de Engenharia de Computação; no segundo semestre dos cursos de Engenharia de Alimentos e Engenharia Química; no quarto semestre dos cursos de Engenharia de Energia e Engenharia de Produção; e, ainda, no quinto semestre do curso de Licenciatura em Física. É composta por quatro créditos teóricos e é ministrada pelos docentes da Engenharia de Computação (UNIPAMPA, 2015a; 2016a; 2016b; 2016c; 2018a; 2018b).

A disciplina de Física I é ofertada no primeiro semestre dos cursos de Engenharia de Alimentos, Engenharia de Energia, Engenharia de Produção e Engenharia Química; no segundo semestre dos cursos de Engenharia de Computação e Licenciatura em Química; e, ainda, no quinto semestre do curso de Licenciatura em Matemática. É composta por quatro créditos teóricos, sendo ministrada 
pelos professores da Licenciatura em Física (UNIPAMPA, 2015a; 2016a; 2016b; 2016c; 2016d; 2017; 2018a).

A disciplina de Cálculo I é ofertada no primeiro semestre dos cursos de Engenharia de Alimentos, Engenharia de Computação, Engenharia de Energia, Engenharia de Produção, Engenharia Química e Licenciatura em Física; e no segundo semestre dos cursos de Licenciatura em Matemática e Licenciatura em Química. É composta por quatro créditos teóricos, sendo ministrada pelos docentes da Licenciatura em Matemática (UNIPAMPA, 2015a; 2016a; 2016b; 2016c; 2016d; 2017; 2018a; 2018b).

A disciplina de Cálculo II é ofertada no segundo semestre dos cursos de Engenharia de Alimentos, Engenharia de Computação, Engenharia de Energia, Engenharia de Produção, Engenharia Química e Licenciatura em Física; e no terceiro semestre dos cursos de Licenciatura em Matemática e Licenciatura em Química. É composta por quatro créditos teóricos, sendo ministrada pelos docentes da Licenciatura em Matemática (UNIPAMPA, 2015a; 2016a; 2016b; 2016c; 2016d; 2017; 2018a; 2018b). A disciplina de Cálculo III é ofertada no terceiro semestre dos cursos de Engenharia de Alimentos, Engenharia de Computação, Engenharia de Energia, Engenharia de Produção, Engenharia Química e Licenciatura em Física; e, ainda, no quarto semestre do curso de Licenciatura em Matemática. É composta por quatro créditos teóricos, sendo ministrada pelos docentes da Licenciatura em Matemática (UNIPAMPA, 2015a; 2016a; 2016b; 2016c; 2017; 2018a; 2018b).

A componente curricular de Fundamentos da Matemática Elementar é ofertada somente ao curso de Licenciatura em Matemática, no decorrer do primeiro semestre. É composta por quatro créditos teóricos e é ministrada pelos docentes da Licenciatura em Matemática (UNIPAMPA, 2017). A disciplina de Introdução à Arquitetura de Computadores é ofertada somente ao curso de Engenharia da Computação, no primeiro semestre. É composta por quatro créditos, sendo um crédito teórico, um crédito prático e dois créditos semipresenciais e é ministrada pelos docentes da Engenharia de Computação (UNIPAMPA, 2016b). A disciplina de Física Geral III é ofertada somente ao curso de Licenciatura em Física, recomendada para o terceiro semestre. É composta por seis créditos teóricos e ministrada pelos docentes da Licenciatura em Física (UNIPAMPA, 2018b). A disciplina de Geometria Analítica é ofertada no primeiro semestre dos cursos de Engenharia de Alimentos, Engenharia de Produção, Engenharia Química e Licenciatura em Física; no segundo semestre da Licenciatura em Química; e, ainda, no terceiro semestre da Licenciatura em Matemática. Além disso, é ofertada como componente complementar no curso de Engenharia de Computação. É composta por quatro créditos teóricos, sendo ministrada pelos docentes da Licenciatura em Matemática (UNIPAMPA, 2015a; 2016a; 2016b; 2016c; 2016d; 2017; 2018b).

A disciplina de Teoria Elementar das Funções é ofertada nos cursos de Licenciatura em Matemática, onde possui quatro créditos, sendo três teóricos e um prático; e, ainda, Licenciatura em Química, onde possui quatro créditos teóricos. Em ambos os casos, é recomendada ao primeiro semestre e é ministrada por docentes da Licenciatura em Matemática (UNIPAMPA, 2016d; 2017). A disciplina de Fenômenos de Transporte II é ofertada no sexto semestre dos cursos de Engenharia de Alimentos e Engenharia Química. É composta por quatro créditos, sendo três teóricos e um prático e é ministrada pelos docentes da Engenharia Química (UNIPAMPA, 2016a; 2016c).

A disciplina de Química Orgânica II é ofertada no quarto semestre dos cursos de Engenharia Química e Licenciatura em Química. É composta por quatro créditos teóricos, sendo ministrada pelos docentes da Licenciatura em Química (UNIPAMPA, 2016c; 2016d). A disciplina de Química Analítica Qualitativa 
é ofertada somente ao curso de Licenciatura em Química, alocada no terceiro semestre. É composta por quatro créditos teóricos, sendo ministrada pelos docentes da Licenciatura em Química (UNIPAMPA, 2016d). A disciplina de Bioquímica é ofertada somente ao curso de Licenciatura em Química, alocada no quinto semestre. É composta por quatro créditos teóricos, sendo ministrada pelos docentes da Licenciatura em Química (UNIPAMPA, 2016d).

A disciplina de Conversação em Espanhol é ofertada somente ao curso de Letras/Línguas Adicionais, alocada no quinto semestre. É composta por cinco créditos, sendo quatro teóricos e um prático e é ministrada pelos docentes do curso de Letras Línguas Adicionais (UNIPAMPA, 2015b). A disciplina de Produção Acadêmico-científica é ofertada no primeiro semestre do curso de Engenharia Química e no quinto semestre de Engenharia de Computação. É composta por dois créditos teóricos, sendo ministrada pelos docentes do curso de Letras/Português (UNIPAMPA, 2016b; 2016c). A disciplina de Softwares na Aprendizagem de Matemática é ofertada como componente curricular complementar no curso de Licenciatura em Matemática. É composta por quatro créditos teóricos e é ministrada pelos professores da Licenciatura em Matemática (UNIPAMPA, 2017). A disciplina de Geometria Plana é ofertada no segundo semestre do curso de Licenciatura em Matemática. É composta por quatro créditos teóricos, sendo três teóricos e um prático, e é ministrada pelos docentes da Licenciatura em Matemática (UNIPAMPA, 2017).

A disciplina de Estrutura de Dados é ofertada no segundo semestre do curso de Engenharia de Computação. É composta por seis créditos, sendo dois teóricos, dois práticos e dois semipresenciais e é ministrada pelos docentes da Engenharia da Computação (UNIPAMPA, 2016b). A disciplina de Laboratório de Física I é ofertada no primeiro semestre dos cursos de Engenharia de Alimentos, Engenharia de Energia, Engenharia de Produção e Engenharia Química; e, ainda, no segundo semestre do curso de Engenharia de Computação. É composta por dois créditos práticos e é ministrada pelos docentes do curso de Licenciatura em Física (UNIPAMPA, 2015a; 2016a; 2016b; 2016c; 2018a). A disciplina de Arquitetura e Organização de Computadores I é ofertada somente ao curso de Engenharia de Computação, ao longo do segundo semestre. É composta por seis créditos, sendo quatro teóricos e dois semipresenciais e é ministrada pelos docentes de Engenharia de Computação (UNIPAMPA, 2016b). A disciplina de Fundamentos de Língua Portuguesa é ofertada somente ao curso de Letras/Português, no primeiro semestre. É composta por quatro créditos, sendo três teóricos e um prático, e é ministrada pelos docentes do curso de Licenciatura em Letras/Português (UNIPAMPA, 2014).

Com base nesses dados, pode-se observar que as disciplinas que foram apontadas com os menores índices de aprovação, maiores índices de reprovação por nota e maiores índices de reprovação por frequência no campus Bagé da Universidade Federal do Pampa, em sua maioria, apresentam alguns aspectos em comum, tais como: são disciplinas ofertadas ao longo dos primeiros semestres do curso; são disciplinas totalmente ou prioritariamente teóricas; e, ainda, são disciplinas predominantemente pertencentes às Ciências Exatas, mais especificamente às áreas de Matemática, de Física e de Computação. Esses dados são compatíveis com outros referentes a diversas instituições (SACCARO; FRANÇA; JACINTO, 2019).

Já foram realizados alguns estudos referentes à evasão na Universidade Federal do Pampa, incluindo alguns que ilustram a quantidade de alunos evadidos pelo tempo que permaneceram no curso. Analisando esses dados, observa-se que, em todos os cursos de graduação ofertados no campus Bagé, a maior parte dos alunos que evade acaba por fazê-lo nos primeiros dois anos do curso 
(MARTINS, 2018). O fato das disciplinas com maiores problemas de reprovação se encontrarem nos primeiros semestres confirma esse fato. Sendo assim, os altos índices de reprovação situados em disciplinas iniciais nos cursos podem ser apontados como uma das possíveis causas dessa evasão precoce. A concentração da reprovação e da evasão nos semestres iniciais é uma tendência que têm sido identificadas com regularidade na literatura internacional, o que reforça a necessidade de construção de estratégias conjuntas para alcançar a sua mitigação.

O questionário referente à reprovação nas disciplinas de Cálculo II e Física I foi enviado por e-mail a 54 discentes reprovados em Física I e 90 discentes reprovados em Cálculo II no semestre anterior à coleta dos dados. Foram obtidas 15 respostas de alunos de Cálculo II e 16 respostas de alunos de Física I, totalizando $16,67 \%$ e $26,63 \%$ de respondentes em relação ao número total de possíveis participantes, respectivamente. A primeira pergunta do questionário se refere ao turno em que os discentes cursaram a disciplina em questão. As respostas obtidas estão dispostas na Tabela 4.

Tabela 4: Turno indicado pelos discentes

\begin{tabular}{ccc}
\hline Turno/Disciplina & Física I & Cálculo II \\
\hline Tarde & 8 & 8 \\
Noite & 8 & 7 \\
\hline
\end{tabular}

Fonte: Autores (2020).

Na pergunta 2, os discentes foram questionados a respeito de como ocorreu a reprovação na disciplina em questão, por nota ou por frequência. As respostas obtidas estão dispostas na Tabela 5.

Tabela 5: Número de alunos reprovados por nota e frequência

\begin{tabular}{ccc}
\hline Categoria/Disciplina & Física I & Cálculo II \\
\hline Reprovação por nota & 12 & 13 \\
Reprovação por frequência & 4 & 2 \\
\hline
\end{tabular}

Fonte: Autores (2020).

Quando questionados, na terceira pergunta, sobre os motivos que levaram à reprovação, os discentes da disciplina de Física I e Cálculo II citaram os fatores dispostos na Tabela 6.

Tabela 6: Motivos indicados pelos discentes como fatores para a reprovação

\begin{tabular}{cc}
\hline Fator indicado & Ocorrências \\
\hline Alta exigência por parte dos docentes & 2 \\
Acúmulo de conteúdos & 6 \\
Metodologia adotada pelo docente & 10 \\
Dificuldade com a disciplina & 4 \\
Incoerência do que é trabalhado em aula com as questões da prova & 2 \\
Falta de exercícios de fixação & 2 \\
Falta de tempo ou dedicação & 7 \\
Problemas pessoais & 6 \\
Falta de base do Ensino Médio & 3 \\
\hline
\end{tabular}

Fonte: Autores (2020). 
No momento em que os discentes apontam a falta de tempo ou dedicação para a referida disciplina, são citadas algumas causas para essa postura, como a necessidade de trabalharem para que possam permanecer na universidade, ou, então, a alta carga horária do curso, sendo necessário cursar, em um mesmo semestre, muitas disciplinas que exigem alta dedicação para que consigam alcançar a aprovação. Há relatos, principalmente de discentes que cursam em turno noturno, de que os mesmos trabalham durante o dia e vão à universidade somente durante o período noturno, chegando tarde e cansados e, dessa maneira, não encontram disponibilidade de tempo em que possam se dedicar da maneira que deveriam aos estudos de seus componentes curriculares. Quando citaram os problemas pessoais como causa para a reprovação, alguns discentes exemplificaram com problemas financeiros ou de saúde.

Quando solicitado aos discentes o número de vezes em que cursaram a disciplina em questão, foram obtidas as respostas dispostas na Tabela 7.

Tabela 7: Número de reprovações dos discentes.

\begin{tabular}{ccc}
\hline $\mathbf{N}^{\circ}$ de reprovações/Disciplina & Física I & Cálculo II \\
\hline Uma vez & 2 & 5 \\
Duas Vezes & 4 & 5 \\
Três Vezes & 8 & 2 \\
Quatro Vezes & 2 & 2 \\
Seis Vezes & 0 & 1 \\
\hline
\end{tabular}

Fonte: Autores (2020).

Grande parte dos discentes aponta a metodologia do docente ou aspectos relacionados a essa questão como sendo uma das causas principais das suas reprovações. Além disso, como as disciplinas citadas são ofertadas no primeiro ano de curso, o discente acaba apresentando algumas dificuldades de adaptação à rotina universitária. Acostumados com o sistema da Educação Básica, enfrentam estranhezas ao ingressar no Ensino Superior, pois esses níveis apresentam grandes diferenças, em diversos aspectos. Há muitos casos em que os discentes deixam de morar com a sua família e migram para outros municípios ou estados a fim de fazer um curso de graduação, situação que gera mudanças cotidianas ainda maiores. Sendo assim, a responsabilidade de se dedicar aos componentes curriculares acaba ficando em segundo plano.

O questionário direcionado aos docentes que ministraram, nos últimos três anos anteriores à coleta de dados, as disciplinas apontadas como sendo as que possuem índices mais preocupantes de reprovação, foi enviado por e-mail a 51 docentes. Foram obtidas 18 respostas, totalizando 35,29\% em relação ao número potencial de participantes. Quando questionados acerca de qual enquadramento é feito para o componente que ministra, no âmbito desta pesquisa, 13 docentes apontaram a lista de menor índice de aprovação, 9 docentes apontaram a lista de maior índice de reprovação por nota e 5 docentes apontaram a lista de maior índice de reprovação por frequência (como há sobreposições nas categorias, esses números superam o total das 18 respostas).

No espaço para apontar as causas pelas quais o seu componente aparece em tais enquadramentos, foram apontados alguns aspectos, os quais estão dispostos na Tabela 8. 
Tabela 8: Fatores relacionados à reprovação apontados pelos docentes.

\begin{tabular}{cc}
\hline Fatores & Ocorrências \\
\hline Educação Básica deficitária & 12 \\
Falta de engajamento por parte dos discentes & 12 \\
Baixas notas de corte para ingresso nos cursos da instituição & 1 \\
Dificuldade dos discentes em assimilar teoria e prática & 3 \\
Falta de organização, autonomia e persistência do discente & 5 \\
Formação inadequada dos docentes & 2 \\
Carga-horária alta & 1 \\
Falta de conhecimento por parte dos discentes de conceitos de & 2 \\
disciplinas anteriores & 2 \\
Ausência de interesse dos discentes nas monitorias ofertadas & pela instituição \\
\hline
\end{tabular}

Fonte: Autores (2020).

Em geral, os docentes apontam os alunos como os principais responsáveis pelas reprovações, apesar de também indicarem falhas no sistema de Educação Básica, que precede o Ensino Superior. No espaço para indicar sugestões para que seja minimizado o problema de baixa aprovação e/ou alta reprovação em seus componentes curriculares, os docentes apontaram algumas opiniões, as quais estão dispostas na Tabela 9.

Tabela 9: Sugestões apontadas pelos docentes.

\begin{tabular}{cc}
\hline Sugestão & Ocorrências \\
\hline Disciplinas/cursos de nivelamento & 5 \\
Incentivar o aluno a se engajar nos componentes & 5 \\
Buscar maneiras de associar o conteúdo com a prática & 1 \\
Fornecer formação continuada aos docentes & 2 \\
Implementação de tutorias ou outros modelos de acompanhamento & 5 \\
Melhorar a concepção das monitorias & 4 \\
Ampliar os espaços de socialização na universidade & 1 \\
\hline
\end{tabular}

Fonte: Autores (2020).

Os docentes apontaram soluções voltadas aos alunos, aos docentes e, também, à instituição, o que indica que pode haver melhora dos índices de aprovação, caso exista colaboração de todos os envolvidos nesse complexo cenário. Observa-se que os docentes se encontram empenhados a provocar estímulos nos alunos, para que se sintam motivados a se engajar mais no curso em que se encontram matriculados. Contudo, alguns aspectos institucionais acabam dificultando na resolução do problema em questão, uma vez que o sistema de concessão de bolsas de monitoria começa a vigorar muito tarde no calendário semestral e as disciplinas, em geral, só passam a ter auxílio de um monitor na metade do semestre letivo.

Também foi citada a maneira de ingresso na universidade como sendo inadequada, visto que são feitos muitos processos seletivos para preencher todas as vagas ofertadas, resultando em ingressos tardios, o que ocasiona grande dificuldade em acompanhar as disciplinas por parte dos discentes que participam desses últimos processos seletivos, já que eles não assistem às aulas iniciais e, consequentemente, apresentam maiores dificuldades. Além disso, os docentes apontam que a procura aos monitores por parte dos discentes é baixa e sugerem que seja instaurado um meio de 
acompanhamento do desempenho acadêmico dos ingressantes, como, por exemplo, a institucionalização de sistemas de tutorias.

\section{CONSIDERAÇÕES FINAIS}

Através do presente estudo, foi possível elencar os componentes curriculares responsáveis pelos menores índices de aprovação, maiores índices de reprovação por nota e maiores índices de reprovação por frequência no campus Bagé da Universidade Federal do Pampa. Constatou-se que os componentes curriculares apontados são, em geral, da grande área das Ciências Exatas, e, em sua maioria, são ofertados ao longo dos primeiros dois anos dos cursos de graduação, momento em que, em geral, é quando ocorre a maior evasão dos discentes (tais resultados não diferem dos encontrados na literatura internacional da área dos estudos de desempenho e evasão estudantil).

Como principais causas da reprovação, foram apontadas pelos discentes a metodologia adotada pelo professor e, pelos docentes, a falta de conhecimentos prévios da Educação Básica. Além disso, ambos os grupos apontaram como causa a falta de tempo ou o engajamento com as disciplinas por parte dos alunos. A transição entre a Educação Básica e o Ensino Superior merece atenção das instituições e alguns mecanismos precisam ser desenvolvidos para minimizar esses efeitos.

O problema da alta reprovação dificilmente será totalmente solucionado, já que ele se mostra de forma ostensiva no cenário do ensino superior em nível mundial. Porém, é possível amenizar os seus efeitos através de algumas ações, tais o desenvolvimento de estratégias para motivá-los a se engajar mais aos componentes curriculares nos quais estão matriculados, aplicando metodologias de ensino que se proponham a estabelecer inovações educativas. Além disso, pode-se instituir meios de acompanhamento do desempenho acadêmico ou ofertar disciplinas e cursos de nivelamento para reduzir o impacto causado pelas dificuldades com os conteúdos que demandam de conhecimentos prévios da Educação Básica.

É possível promover a oferta de turmas menores e diminuir, continuamente, as turmas multicurso, alinhando os docentes das disciplinas iniciais com os Projetos Pedagógicos de Curso implementados, de maneira que mesmo o docente das consideradas áreas básicas crie um maior elo da disciplina ministrada com o curso de graduação em que ela está inserida, bem como um estabelecimento de maior vínculo e identidade desse docente com o curso. Para isso, é necessário aprimorar o sistema de matrículas, de modo que as vagas de uma mesma turma sejam destinadas, predominantemente, a discentes de um único curso de graduação. Também, é possível promover uma maior gestão na alocação dos docentes que atendem os componentes de início de curso, promovendo formação continuada voltada às dificuldades dos discentes de adaptação ao ensino superior que vêm sendo constatadas e, assim, serem construídas estratégias consistentes e contínuas para lidar com essa problemática de forma situada. 


\section{REFERÊNCIAS}

ANDERTON, Ryan S.; EVANS, Tess; CHIVERS, Paola T. Predicting academic success of health science students for first year anatomy and physiology. International Journal of Higher Education, Beaver Creek, Canadá, v. 5, n. 1, p. 250-260, 12 jan. 2016. Disponível em: http://www.sciedu.ca/journal/index.php/ijhe/article/view/8513/5250. Acesso em: 20 abr. 2020.

AMARAL, Liliane Belo do. Causas da evasão discente no curso de Filosofia de uma instituição pública de ensino superior. Universidade de Brasília, Brasília (2009). Disponível em: http://bdm .unb.br/bitstream/10483/1261/1/2009_LilianeMariaBelodoAmaral.pdf. Acesso em:10 jun.2020.

BRASIL. Lei n 9394, de 20 de dezembro de 1996. Estabelece as Diretrizes e Bases da Educação Nacional. Diário Oficial da União. Brasília, DF: 20 de dezembro de 1996.

BRASIL. Lei no 11640 de 11 de janeiro de 2008. Institui a fundação da Universidade Federal do Pampa - UNIPAMPA e dá outras providências. Diário Oficial da União. Poder Executivo. Brasília, DF, 11 de janeiro de 2008.

CATANI, Afrânio Mendes; HEY, Ana Paula; GILIOLI, Renato de Sousa Porto. PROUNI: democratização do acesso às Instituições de Ensino Superior? Educ.Rev. n.28, p. 125-140, 2006.

CONSELHO NACIONAL DE EDUCAÇÃO. Câmara de Educação Superior. Resolução CNE/CES n 11, de 11 de março de 2002. Institui Diretrizes Curriculares Nacionais do Curso de Graduação em Engenharia. Brasília, DF, 11 de março de 2002.

DIOGO, Maria Fernanda; RAYMUNDO, Luana dos Santos; WILHELM, Fernanda; ANDRADE, Sílvia Patricia Cavalheiro de; LORENZO, Flora Moura; ROST, Flávia Trento; BARDAGI, Marúcia Patta. Percepções de coordenadores de curso superior sobre evasão, reprovações e estratégias preventivas.

Avaliação, Campinas, v. 21, n. 1. 2016. Disponível em: http://www.scielo.br/scielo.php?script=sci_arttext\&pid=S1414-

$40772016000100125 \&$ lng=pt\&tlng=pt. Acesso em 14 de maio de 2019.

GENTIL, Viviane. Expansão, interiorização e democratização do acesso à educação superior pública: o caso da UNIPAMPA. Tese (Doutorado) - Programa de Pós-graduação em Educação. Pontifícia Universidade Católica (PUC-RS), Porto Alegre, 2017.

GONZÁLES-CAMPOS, José Alejandro; CARVAJAL-MUQUILLAZA, Cristian Manuel; ASPEÉ-CHACÓN, Juan Elías. Modelación de la deserción universitaria mediante cadenas de Markov. Uniciencia, Heredia, Costa Rica, vol. 34, n.1, p. 129-146. jan-Jun, 2020.

HERNÁNDEZ-JIMÉNEZ, María Teresa; MOREIRA-MORA, Tania Elena; SOLÍS-SALAZAR, Martín, FERNÁNDEZ-MARTÍN, Tatiana. Estudio descriptivo de variables sociodemográficas y motivacionales asociadas a la deserción: la perspectiva de personas universitarias de primer ingreso. Revista Educación, San José, Costa Rica, v. 44, n. 1, p. 1-19, enero-jun. 2020. Disponível em: http://www.redalyc.org/articulo.oa?id=44060092023. Acesso em: 20 abr. 2020.

JACOMINI, Maria Aparecida. Educar sem reprovar: desafio de uma escola para todos. Educação e Pesquisa, São Paulo, v. 35, n. 3, p.557-572. 2009. Disponível em:http://www.scielo.br/scielo.php?script=sci_arttext\&pid=S151797022009000300010\&1n $\mathrm{g}=\mathrm{pt \& nrm}=$ iso. Acesso em 14 de maio de 2019.

LEITE, Sérgio Antônio Silva; KAGER, Samantha. Efeitos aversivos das práticas de avaliação da aprendizagem escolar. Revista Ensaio: Avaliação políticas públicas educacionais. Rio de Janeiro, v. 17, n.62, p. 109-134, jan./mar. 2009. 
LOBO, Maria Beatriz de Carvalho Melo. Panorama da Evasão no Ensino Superior Brasileiro: Aspectos Gerais das Causas e Soluções. Associação Brasileira de Mantenedoras de Ensino Superior. Cadernos, $\quad$ n. 25, 2012, $23 \quad$ p. $\quad$ Disponível http://www.institutolobo.org.br/imagens/pdf/artigos/art_087.pdf. Acesso em 01 de maio de 2019.

LÓPEZ-PASTOR, Victor Manuel. Evaluación formativa y compartida: evaluar para aprender y la implicación del alumnado en los procesos de evaluación y aprendizaje. LÓPEZ-PASTOR, Victor Manuel \& PÉREZ-PUEYO, Ángel (orgs.). Evaluación formativa y compartida en Educación: experiencias de éxito en todas las etapas educativas. León: Universidad de León, 2017. p. 34-69.

MARCHIORO, Dáfni. Fernanda. Zenedin. et al. A Unipampa no contexto atual da educação superior. Avaliação, v.12, n.4, p.703-717, dez. 2007.

MARTINS, Cristiano Ribeiro. Gestão Universitária: um estudo de caso sobre a evasão em uma instituição pública de ensino. 2019. 65f. Trabalho de Conclusão de Curso (Graduação Curso de Administração) - Universidade da Região da Campanha, Bagé, Rio Grande do Sul, 2018.

MENDES, Olenir Maria. Avaliação formativa no Ensino Superior: reflexões e alternativas possíveis. Currículo e avaliação na educação superior. São Paulo: Junqueira \& Marin. 2005. p. 175 - 197.

MISSIOL, Daniele; CARVALHO, Natan da Cruz de; SOUZA, Tainã Luís de; LEIVAS, Fabio Gallas; BRUM, Daniela dos Santos; MELLO, Elena Maria Billig. Reflexões sobre os índices de retenção e evasão no curso de Medicina Veterinária da Unipampa. Educação Brasileira, Brasília, v. 38, n. 76/77, p. 178201, 2016.

MORENO, Jacqueline Elizabet; CHIECHER, Analía Claudia. Abandono en carreras de Ingeniería. Un estudio de los aspectos académicos, sociodemográficos, laborales y vitales. Cuadernos de Investigación Educativa, Montevideo, Uruguay, v. 10, n. 2, p. 73-90, 2019. Disponível em: https://revistas.ort.edu.uy/cuadernos-deinvestigacion-educativa/article/view/2908. Acesso em: 20 abr. 2020.

RAUEN, Fábio. Roteiros de pesquisa. Rio do Sul/SC: Nova Era, 2006.

SACCARO, Alice; FRANÇA, Marco Túlio Aniceto; JACINTO, Paulo de Andrade. Fatores associados à evasão no ensino superior brasileiro: um estudo de análise de sobrevivência para os cursos das áreas de Ciência, Matemática e Computação e de Engenharia, Produção e Construção em instituições públicas e privadas. Estudos Econômicos, São Paulo, v. 49, n. 2, p. 337-373, abr.-jun. 2019. Disponível em: http://www.scielo.br/scielo.php?script=sci_arttext\&p id=S010141612019000200337. Acesso em: 20 abr. 2020.

SOUSA, António Carlos Corte-Real de; OLIVEIRA, Carlos Alberto Bragança de; BORGES, José Luís Cabral Moura. Utilização do sucesso acadêmico para prever o abandono escolar de estudantes do ensino superior: um caso de estudo. Educação e Pesquisa, São Paulo, v. 44, p. 1-19, 17 out. 2018. Disponível em: http://www.scielo.br/scielo.php?script=sci_arttext\&p id=S151797022018000100492. Acesso em: 20 abr. 2020.

TINTO, Vincent. Dropout from higher education: a theoretical synthesis of recent research. Review of Educational Research, Washington, v. 45, n. 1, p. 89-125, Winter, 1975.

TINTO, Vincent. Leaving College: Rethinking The Causes and Cures of Student Attrition. 2 ed. Chicago: University of Chicago Press, 1993.

TINTO, Vincent. Completing college: rethinking institutional action. Chicago: The University of Chicago Press, 2012. 
TINTO, Vicent. Through the Eyes of Students. Journal of College Student Retention: Research, Theory \& Practice, Reino Unido, vol. 19, n3, p. 254-269, 2017.

UNIVERSIDADE FEDERAL DO PAMPA. Campus Bagé. Projeto Político-Pedagógico do Curso de Engenharia de Alimentos. 2016a. Disponível em: http://www.scielo.br/pdf/ep/v43n1/1517-9702ep-S1517-9702201605145723.pdf. Acesso em 25 de abril de 2019.

UNIVERSIDADE FEDERAL DO PAMPA. Campus Bagé. Projeto Político-Pedagógico do Curso de Engenharia de Computação. 2016b. Disponível em: http://dspace.unipampa.edu.br/bitstream/riu/96/3/PPC\%20Engenharia\%20de\%20Computacao_Bag \%C3\%A9.pdf. Acesso em 25 de abril de 2019.

UNIVERSIDADE FEDERAL DO PAMPA. Campus Bagé. Projeto Político-Pedagógico do Curso de Engenharia de Energia. 2018a. Disponível em: http://dspace.unipampa.edu.br/bitstream/riu/95/6/PPC Engenharia de Energia Bag\%C3\%A9.pdf. Acesso em 25 de abril de 2019.

UNIVERSIDADE FEDERAL DO PAMPA. Campus Bagé. Projeto Político-Pedagógico do Curso de Engenharia de Produção. 2015a. Disponível em: http://dspace.unipampa.edu.br/bitstream/riu/94/3/PPC_Engenharia\%20de\%20Produ\%C3\%A7\%C3 \%A30_Bag\%C3\%A9.pdf. Acesso em 25 de abril de 2019.

UNIVERSIDADE FEDERAL DO PAMPA. Campus Bagé. Projeto Político-Pedagógico do Curso de Engenharia Química. 2016c. Disponível em: http://dspace.unipampa.edu.br/bitstream/riu/93/3/PPC_Eng_Quimica_Bag\%C3\%A9.pdf. Acesso em 25 de abril de 2019.

UNIVERSIDADE FEDERAL DO PAMPA. Campus Bagé. Projeto Político-Pedagógico do Curso de Licenciatura em Física. 2018b. Disponível em: http://dspace.unipampa.edu.br/bitstream/riu/92/5/PPC F\%C3\%8DSICA.pdf. Acesso em 25 de abril de 2019.

UniVersidade federal do PAMPA. Campus Bagé. Projeto Político-Pedagógico do Curso de Licenciatura em Matemática. 2017. Disponível em: http://dspace.unipampa.edu.br/bitstream/riu/89/6/PPC\%20Matem\%C3\%A1tica_Bag\%C3\%A9.pdf. Acesso em 25 de abril de 2019.

UNIVERSIDADE FEDERAL DO PAMPA. Campus Bagé. Projeto Político-Pedagógico do Curso de Licenciatura em Química. 2016d. Disponível em: http://dspace.unipampa.edu.br/bitstream/riu/87/4/PPC\%20Quimica 2016.pdf. Acesso em 25 de abril de 2019.

UNIVERSIDADE FEDERAL DO PAMPA. Campus Bagé. Projeto Político-Pedagógico do Curso de Licenciatura em Música. 2016e. Disponível em: http://dspace.unipampa.edu.br/bitstream/riu/88/8/PPC_M\%C3\%BAsica_Bag\%C3\%A9.pdf. Acesso em 25 de abril de 2019.

UNIVERSIDADE FEDERAL DO PAMPA. Campus Bagé. Projeto Político-Pedagógico do Curso de Licenciatura em Letras - Línguas Adicionais: Inglês, Espanhol e Respectivas Literaturas. 2015b. 
UNIVERSIDADE FEDERAL DO PAMPA. Campus Bagé. Projeto Político-Pedagógico do Curso de Licenciatura em Letras - Português e Literaturas de Língua Portuguesa. 2014. Disponível em:

http://dspace.unipampa.edu.br/bitstream/riu/90/1/PPC\%20Letras\%20Portugu\%C3\%AAs_Bag\%C3 \%A9.pdf. Acesso em 25 de abril de 2019.

UNIVERSIDADE FEDERAL DO PAMPA. Conselho Universitário. Resolução n 29 de 28 de abril de 2011. Aprova as normas básicas de graduação, controle e registro das atividades acadêmicas. Bagé, RS, 28 de abril de 2011.

UNIVERSIDADE FEDERAL DO PAMPA. SISU UNIPAMPA. S/d. Disponível em: https://www12.unipampa.edu.br/sisu/cursos/. Acesso em 01 de maio de 2019. 